\title{
Searching for Bacterial Biofilm in Recurrent Cholangitis in Primary Sclerosing Cholangitis: A Case Presentation and Introduction of an Unexplored Disease Mechanism
}

\author{
Alyssa Y. Choi ${ }^{1}$, Florencia Jalikis ${ }^{2}$, Maria Westerhoff ${ }^{2}$, Sarag Boukhar ${ }^{3}$, Elinor Pulcini ${ }^{4}$, \\ Chris Damman ${ }^{5}$ and Lei Yu*5 \\ ${ }^{1}$ Department of Internal Medicine, University of Washington, Seattle, Washington, USA; ${ }^{2}$ Department of Pathology, University of \\ Washington, Seattle, Washington, USA; ${ }^{3}$ Department of Pathology, University of Iowa, Iowa City, Iowa, USA; ${ }^{4}$ Center for Biofilm \\ Engineering, Montana State University, Bozeman, Montana, USA; ${ }^{5}$ Division of Gastroenterology, University of Washington, \\ Seattle, Washington, USA
}

\begin{abstract}
Inflammation and fibrosis of the bile ducts are the defining pathological characteristics of primary sclerosing cholangitis (PSC). A previously unexplored mechanism for recurrent cholangitis, one of PSC's most common presentations, is bacterial colonization of the biliary epithelium in the form of biofilm, which may confer resistance to antibiotics and host phagocytic machinery. The aim of the current study was to assess whether bacteria could be seen on the liver explant and whether they organized in the form of biofilm. An explanted PSC liver from a 60-year-old male who suffered from recurrent cholangitis was formalin-fixed, paraffinembedded and Gram stained. The specimens were observed under light microscopy. Neither bacteria nor biofilm were detected. We did not detect bacteria or biofilm in the liver explant of a single PSC patient with recurrent cholangitis using standard light microscopy. We suspect this may be in part due to techniques related to tissue preservation and microscopy.

Citation of this article: Choi AY, Jalikis F, Westerhoff M, Boukhar S, Pulcini E, Damman C, et al. Searching for bacterial biofilm in recurrent cholangitis in primary sclerosing cholangitis: A case presentation and introduction of an unexplored disease mechanism. J Clin Transl Hepatol 2018;6(1):114-118. doi: $10.14218 /$ JCTH.2017.00029.
\end{abstract}

\section{Introduction}

Primary sclerosing cholangitis (PSC) is a liver disease defined by inflammation, fibrosis and stricture of the intra- and extrahepatic bile ducts. ${ }^{1}$ It is a leading indication for liver transplantation in adults, despite its relatively low prevalence of $1-15$ per 100,000 people. ${ }^{1}$ A subset of patients with PSC

Keywords: Primary sclerosing cholangitis; Recurrent cholangitis; Biofilm. Abbreviations: AASLD, American Association for the Study of Liver Diseases EASL, European Association for the Study of the Liver; MELD, model for end stage liver disease; PSC, primary sclerosing cholangitis.

Received: 29 April 2017; Revised: 9 November 2017; Accepted: 11 November 2017

* Correspondence to: Lei Yu, Division of Gastroenterology, University of Washington, 1959 NE Pacific Street, Box 356175, Seattle, WA 98195-6175, USA. Tel: +1-206-598-2212, Fax: +1-206-598-3884, E-mail: leiy@medicine. washington.edu experience fever, right upper quadrant pain and jaundice. ${ }^{2}$ While these symptoms may resolve without specific treatment, a proportion of patients have repeated cholangitis with positive bacterial or fungal cultures from blood or bile, despite antibiotic therapy. ${ }^{3}$

In the context of liver transplant allocation, the most current definition of recurrent bacterial cholangitis includes the following criteria: 1 . at least two episodes of cultureproven, non-iatrogenic cholangitis during a 6-month period; 2. cholangitis episodes that have occurred despite recent or active treatment with antibiotics; 3 . single episode of cholangitis with severe sepsis-related complications. ${ }^{2}$ This unique syndrome of recurrent bacterial cholangitis in PSC is an accepted indication for liver transplantation, regardless of whether or not advanced liver failure is present. ${ }^{4}$

A previously unexplored explanation for the recurrent nature of cholangitis in PSC is chronic bacterial colonization of the biliary epithelium in the form of biofilms. It is now widely accepted that most bacteria in nature live in "sessile" communities surrounded by a glycocalyx matrix. Such arrangement, in contrast to the planktonic (single cell) form of existence, is associated with a distinctive bacterial phenotype that confers resistance to antibiotics and contributes to the host's phagocytic machinery. ${ }^{5}$

We herein describe a case of a PSC patient with recurrent bacterial cholangitis who underwent successful liver transplantation. The primary aim was to assess whether bacteria could be "seen" on the liver explant and whether they organized in the form of biofilm.

\section{Case report}

A 60-year-old white male with PSC diagnosed 15 years ago presented with fever, chills, right upper quadrant abdominal pain and disorientation. In the past 2 years, he had been hospitalized with similar symptoms more than six times. His medical co-morbidities included Crohn's disease managed by mesalamine, peptic ulcer disease and Type II diabetes. He had focal noncaseating granulomas on his ileum and colon biopsies without active inflammation. His cirrhosis was complicated by mild jaundice and encephalopathy. His cholangiogram showed diffuse biliary strictures and choledocholithiasis without a dominant stricture. 
During episodes of abdominal pain, fevers and chills, carbapenem-resistant Eschericheria coli and Enterococcus faecium grew from blood cultures on multiple occasions. In contrast, growth from biliary cultures was always polymicrobial, including $E$, coli, Enterococcus faecalis and E. faecium, Stenotrophomonas maltophilia, Staphylococcus aureus, Corynebacterium amycolatum and yeast. In addition to antibiotics, treatment for his cholangitis included sphincterotomy, common bile duct dilation and stenting. Usually, his symptoms would improve temporarily after each ERCP. Despite having undergone internal-external biliary duct drainage several months before his transplant, he continued to experience culture-positive cholangitis and sepsis.

At the time of liver transplant, the patient's model for endstage liver disease (commonly known as MELD) score was 14 (total bilirubin: $2.5 \mathrm{mg} / \mathrm{dL}$, creatinine: $0.56 \mathrm{mg} / \mathrm{dL}$, international normalized ratio: 1.5 ), with additional points approved for recurrent cholangitis. According to the surgeon, pus was oozing from the liver at the time of hepatectomy. On postoperative day 4, the patient developed daptomycin-resistant enterococcus bacteremia, which was treated successfully with linezolid. The source was unknown. At the time of this writing (1 year after transplant), the patient was clinically well.

\section{Pathological description}

Gross examination of the explanted liver demonstrated nodular distortion of the parenchyma, consistent with cirrhosis. Thirteen representative sections of the liver explant (from segments 2, 4 and 8, the caudate lobe and the hilum) were submitted for histological evaluation. Microscopy was significant for patchy bile duct loss (Fig. 1A) and nodular formation (Fig. 1B), consistent with the patient's history of PSCassociated cirrhosis. Some of the large bile ducts had large collections of neutrophils (Fig. 1C), and the bile duct epithelium showed active cholangitis (Fig. 1D). Light microscopy on Gram-stained, formalin-fixed and paraffin-embedded explant blocks did not show any bacteria, fungi or biofilm.

\section{Discussion}

Since Hoffman described the first official case of primary sclerosing cholangitis in $1867,{ }^{6}$ its pathogenesis remains incompletely understood. While inflammation and fibrosis of the biliary tree are the defining pathological characteristics, the resulting biliary strictures are not always associated with true bacterial cholangitis. Among patients listed for liver transplantation for PSC, only one-fifth had two or more episodes of cholangitis. ${ }^{7,8}$ To our knowledge, no study has examined factors associated with recurrent bacterial cholangitis in PSC patients.

Based on physio-anatomical considerations and culture results, the gastrointestinal tract is the most likely source of infectious organisms in PSC-associated cholangitis. How exactly enteric organisms gain "entry" into bile, however, is unclear. The disease's unique association with inflammatory bowel disease makes the portal vein a potential route, as bacteria translocate across an inflamed gastrointestinal tract. While animal studies have established portal vein as a route of bacteria entry into bile, ${ }^{9}$ in the most carefully performed human study to date, surgical sampling of colitis patients without PSC failed to show portal venous bacteremia. ${ }^{10}$
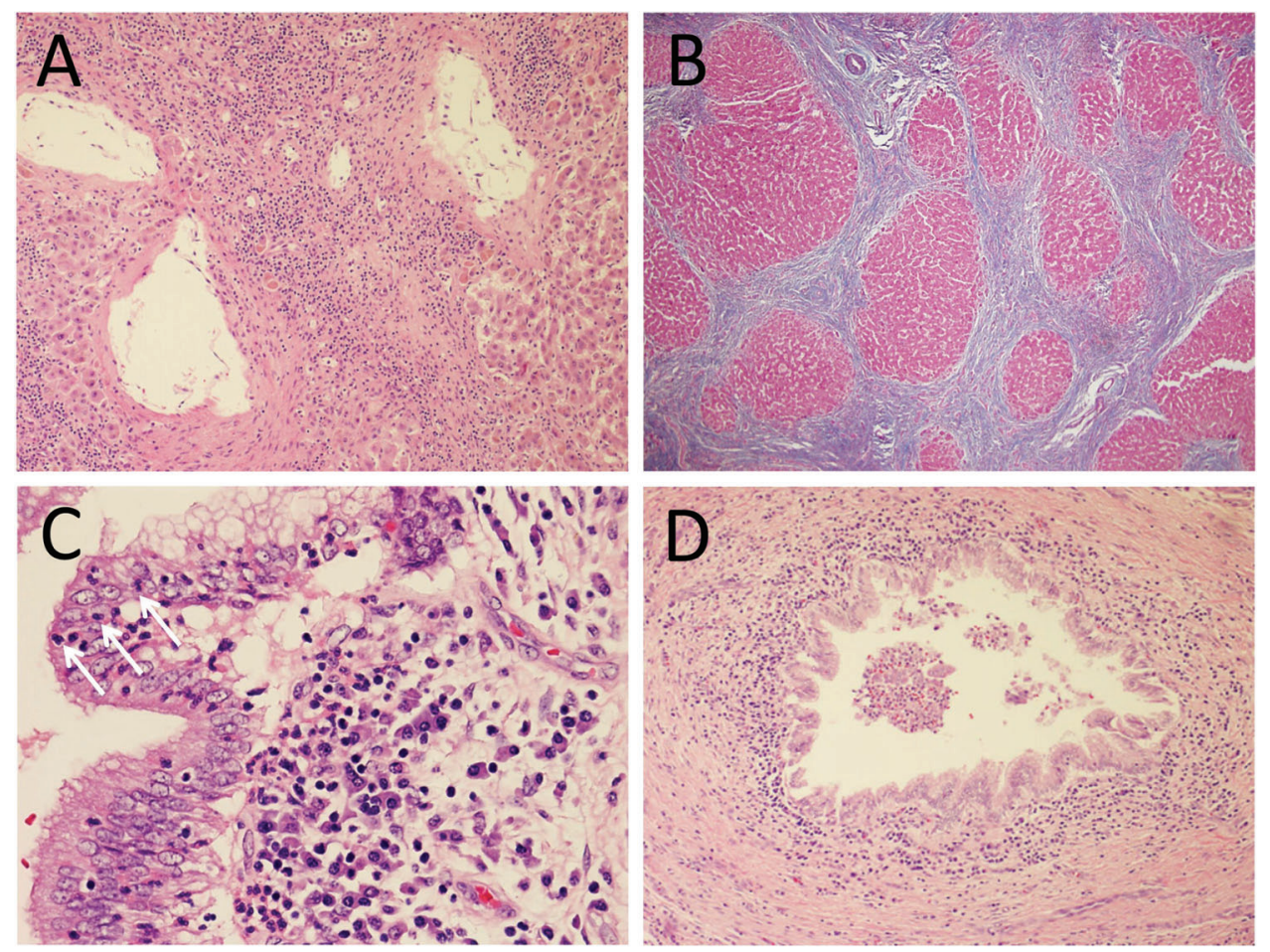

Fig. 1. (A) Portal tract with preserved vascular structures, without accompanying bile duct, consistent with the patient's diagnosis of PSC; H\&E stain, $100 \times$. (B) Trichrome stain highlights cirrhotic liver parenchyma; MT stain, 100 $\times$. (C) Bile duct with numerous intraepithelial neutrophils (arrows); H\&E stain, $400 \times$. (D) Large bile duct with intraluminal collections of neutrophils; H\&E stain, 100 $\times$. 
In Asian patients with recurrent pyogenic cholangitis commonly associated with hepatolithiasis and clonorchis infection, only $15 \%$ of patients had bacteria cultured from portal venous blood at the time of laparotomy. ${ }^{11}$ No similar study has been conducted in Caucasian patients with PSC.

Reflux of enteric organisms through the sphincter of Oddi was thought to be another route of bacterial entry into bile in non-PSC-associated cholangitis. ${ }^{12-14}$ Supporting this concept, Olsson et al. ${ }^{15}$ reported that recent endoscopic instrumentation had the strongest association with positive bacterial culture in PSC liver explant specimens, regardless of whether fever, infection or dominant strictures were present or not. Identifying the exact route of bacteria entry into bile-translocation through the portal vein versus retrograde migration through the sphincter of Oddi-may be important to guide treatment and management strategies of recurrent cholangitis.

The presence of dominant strictures of the bile ducts (defined by Rudolph et al. ${ }^{16}$ as $<1.5 \mathrm{~mm}$ of the common bile duct and $<1.0 \mathrm{~mm}$ of the common hepatic duct within $2 \mathrm{~cm}$ of the bifurcation) is another logical etiologic suspect in recurrent cholangitis. This anatomical finding occurs in approximately $50 \%$ of PSC patients during their disease course. ${ }^{17}$ Elevated intrabiliary pressure from obstruction can distort tight junctions between hepatocytes, facilitating entry of bacteria into bile. ${ }^{18}$ In addition, biliary obstruction leads to a decrease in phagocytic activity of hepatic Kupffer cells. ${ }^{19}$ While dominant strictures are associated with liver disease progression and positive bacterial culture from bile, it is unclear whether they were associated with clinical evidence of cholangitis. ${ }^{17,20}$

In the study by Pohl et al., ${ }^{20}$ in which a strong association was found between positive bacterial culture in bile and dominant strictures, the majority (36 of 37 ) of patients with dominant strictures had undergone multiple endoscopic instrumentation procedures prior to bile sample collection, implicating bacterial contamination. More importantly, experience from our case suggests that dilation of the biliary tree may not be effective, likely because of the diffuse nature of intrahepatic strictures, and that disruption of the sphincter of Oddi has the potential to promote additional enteric bacteria migration into the biliary system.

The current 2010 American Association for the Study of Liver Diseases (AASLD) practice guidelines do not recommend routine antibiotics in patients with recurrent cholangitis in PSC. ${ }^{21}$ While several antibiotics improve liver biochemistry in PSC patients without affecting liver histology or endoscopic features (Table 1), none of the studies to date have specifically investigated whether patients with or without bacterial cholangitis respond differently to treatment. ${ }^{23,24,36-42}$ Occasionally, however, patients developed recurrent cholangitis later in their disease course without an initial presentation of cholangitis at the start of the study. ${ }^{23}$ Our case provides evidence (based on culture results) that standard oral antibiotics, even when given long-term, were not able to suppress cholangitis, although intravenous formulation did improve the acute presentations of fever and abdominal pain.

Our interest in exploring biofilm formation in PSC patients with recurrent cholangitis was based on several lines of evidence. First, the presence of bacteria has been unequivocally demonstrated using traditional culture-based methods in PSC patients with advanced liver disease. ${ }^{15}$ Second, the recurrent nature of cholangitis suggests a unique bacterial ecology favoring its survival within a compromised host. Third, a molecular-based method for microbiota determination and imaging techniques for biofilm analysis have firmly established the role of bacterial colonization and infection in the pathogenesis of cystic fibrosis a disease complicated by recurrent pneumonia and having a phenotype similar to recurrent cholangitis. ${ }^{25}$ These methodological (and conceptual) advances may help define the role of bacteria in PSC as well. Fourth, the presence of biofilm presents itself as

Table 1. Reported series evaluating the role of antibiotics for treatment of $\mathrm{PSC}^{23,24,36-42}$

\begin{tabular}{|c|c|c|c|c|c|c|}
\hline Study & Year & Design & Subjects & Antibiotics & Parameters & Response \\
\hline Farkkila et al. & 2004 & RCT & 80 & $\begin{array}{l}\text { Metronidazole, } \\
\text { UCDA }\end{array}$ & $\begin{array}{l}\text { ALP, ALT, AST, GGT, Mayo } \\
\text { risk score, liver histology }\end{array}$ & Partial \\
\hline Silveria et al. & 2009 & Pilot study & 16 & Minocycline & $\begin{array}{l}\text { ALP, AST, total bilirubin, } \\
\text { direct bilirubin, PT, } \\
\text { albumin, Mayo risk score }\end{array}$ & Partial \\
\hline Tabibian et al. & 2013 & RCT & 35 & $\begin{array}{l}\text { Vancomycin vs. } \\
\text { Metronidazole }\end{array}$ & $\begin{array}{l}\text { ALP, total bilirubin, CRP, } \\
\text { Mayo risk score }\end{array}$ & Partial \\
\hline Davies et al. & 2008 & Observational & 14 & Oral vancomycin & ALT, GGT, ESR, liver histology & Positive \\
\hline Misitilis et al. & 1965 & Case report & 7 & Tetracycline & $\begin{array}{l}\text { ALP, total bilirubin, } \\
\text { liver histology }\end{array}$ & Negative \\
\hline Boner et al. & 2007 & Case report & 1 & Azithromycin & $\begin{array}{l}\text { ALP, ALT, AST, GGT, } \\
\text { total bilirubin }\end{array}$ & Positive \\
\hline Rankin et al. & 1959 & Case report & 5 & Tetracycline & $A L P, A L T, A L T$ & Positive \\
\hline Cox and Cox & 1998 & Case report & 3 & Vancomycin (oral) & $\begin{array}{l}\text { ALT, GGT, ESR, } \\
\text { liver histology, ERCP }\end{array}$ & Positive \\
\hline Mathew et al. & 1983 & Case report & 1 & Metronidazole & $\begin{array}{l}\text { Total bilirubin, clinical signs } \\
\text { and symptoms }\end{array}$ & Positive \\
\hline
\end{tabular}

* = pediatric 
a novel therapeutic target in PSC with or without cholangitis. For example, rifampin, a second-line agent for the treatment of pruritis, ${ }^{26}$ penetrates biofilm in prosthetic hardwareassociated methicillin-resistant $S$. aureus bacteremia. ${ }^{27}$ More recently, aspirin, an anti-biofilm agent, was found to be associated with a significantly lower risk of cholangiocarcinoma. ${ }^{28,29}$ Finally, formation of bacterial biofilm in vitro and bacterial membrane integrity are affected by the presence of bile. ${ }^{30-32}$ It is possible that the higher mortality observed in the high-dose ursodeoxycholic acid arm of the recent PSC trial $^{33}$ was related to excessive enrichment of bile with ursodeoxycholic acid, rendering it too hydrophilic to suppress biofilm formation from pathogenic enteric organisms.

Other than the possibility that biofilm does not exist in PSC-associated recurrent cholangitis, formalin fixation, which affects intestinal biofilm preservation in inflammatory bowel disease, ${ }^{34}$ may have hindered our ability to detect biliary biofilm. In addition, while standard light microscopy is an established method for detecting biofilm, scanning electron microscopy and fluorescence in situ hybridization have also been used. ${ }^{35}$ Even though no studies to date have directly compared the sensitivity and specificity of these microscopies, these more advanced methods, which were not available to us, may improve our ability to detect biliary biofilm. An effort to organize a larger study using proper tissue preservation technique, as well as more sophisticated microscopy, is currently underway.

\section{Conflict of interest}

The authors have no conflict of interests related to this publication.

\section{Author contributions}

Study concept and design, interpretation of findings, drafting and revising the article (AC), reviewing pathology and interpretation of findings, revising the article (FJ), reviewing pathology and interpretation of findings, revising the article (MW), reviewing pathology and interpretation of findings, revising the article (SB), interpretation of findings, revising the article (EP), contributed to study concept and design, interpretation of findings, revising the article (CD), study concept, interpretation of findings, drafting and revising the article (LY).

\section{References}

[1] Karlsen TH, Boberg KM, Schrumpf E. Primary Sclerosing Cholangitis. In: Boyer TD, Manns MP, Sanyal AJ, ed. Zakim \& Boyer's Hepatology: A Textbook of Liver Disease (Sixth Edition). Philadelphia: Elsevier, 2011:754.

[2] Gores G], Gish RG, Shrestha R, Wiesner RH. Model for end-stage liver disease (MELD) exception for bacterial cholangitis. Liver Transpl 2006;12: S91-S92. doi: 10.1002/It.20966.

[3] Olsson R, Broomé U, Danielsson A, Hägerstrand I, Järnerot G, Lööf L, et al. Spontaneous course of symptoms in primary sclerosing cholangitis: relationships with biochemical and histological features. Hepatogastroenterology 1999;46:136-141.

[4] Goldberg DS, French B, Thomasson A, Reddy KR, Halpern SD. Current trends in living donor liver transplantation for primary sclerosing cholangitis. Transplantation 2011;91:1148-1152. doi: 10.1097/TP.0b013e31821694b3.

[5] Donlan RM, Costerton JW. Biofilms: survival mechanisms of clinically relevant microorganisms. Clin Microbiol Rev 2002;15:167-193. doi: 10.1128/CMR. 15.2.167-193.2002.

[6] Hoffman CEE. Verschluss der Gallenwege durch Verdickung der Wandungen. Arch Pathol Anat Physiol 1867;39:206-215. doi: 10.1007/BF01879134.
[7] Goldberg D, French B, Thomasson A, Reddy KR, Halpern SD. Waitlist survival of patients with primary sclerosing cholangitis in the model for end-stage liver disease era. Liver Transpl 2011;17:1355-1363. doi: 10.1002/It.22396.

[8] Goldberg DS, Camp A, Martinez-Camacho A, Forman L, Fortune B, Reddy KR. Risk of waitlist mortality in patients with primary sclerosing cholangitis and bacterial cholangitis. Liver Transpl 2013;19:250-258. doi: 10.1002/lt. 23587.

[9] Sung JY, Shaffer EA, Olson ME, Leung JW, Lam K, Costerton JW. Bacterial invasion of the biliary system by way of the portal-venous system. Hepatology $1991 ; 14: 313-317$. doi: 10.1002/hep.1840140218.

[10] Palmer KR, Duerden BI, Holdsworth CD. Bacteriological and endotoxin studies in cases of ulcerative colitis submitted to surgery. Gut $1980 ; 21$ : 851-854. doi: 10.1136/gut.21.10.851.

[11] Ong GB. A study of recurrent pyogenic cholangitis. Arch Surg 1962;84:199225. doi: 10.1001/archsurg.1962.01300200047004.

[12] Gregg JA, De Girolami P, Carr-Locke DL. Effects of sphincteroplasty and endoscopic sphincterotomy on the bacteriologic characteristics of the common bile duct. Am J Surg 1985;149:668-671. doi: 10.1016/S00029610(85)80152-5.

[13] Sung JY, Leung JW, Shaffer EA, Lam K, Olson ME, Costerton JW. Ascending infection of the biliary tract after surgical sphincterotomy and biliary stenting. J Gastroenterol Hepatol 1992;7:240-245. doi: 10.1111/j.1440-1746. 1992.tb00971.x

[14] Toouli J, Geenen JE, Hogan WJ, Dodds WJ, Arndorfer RC. Sphincter of Oddi motor activity: a comparison between patients with common bile duct stones and controls. Gastroenterology 1982;82:111-117.

[15] Olsson R, Björnsson E, Bäckman L, Friman S, Höckerstedt K, Kaijser B, et al. Bile duct bacterial isolates in primary sclerosing cholangitis: a study of explanted livers. J Hepatol 1998;28:426-432. doi: 10.1016/S0168-8278 (98)80316-4.

[16] Stiehl A, Rudolph G, Sauer P, Benz C, Stremmel W, Walker S, et al. Efficacy of ursodeoxycholic acid treatment and endoscopic dilation of major duct stenoses in primary sclerosing cholangitis. An 8-year prospective study. J Hepatol 1997;26:560-566. doi: 10.1016/S0168-8278(97)80421-7.

[17] Rudolph G, Gotthardt D, Klöters-Plachky P, Kulaksiz H, Rost D, Stiehl A. Influence of dominant bile duct stenoses and biliary infections on outcome in primary sclerosing cholangitis. J Hepatol 2009;51:149-155. doi: 10. 1016/j.jhep.2009.01.023.

[18] De Vos R, Desmet VJ. Morphologic changes of the junctional complex of the hepatocytes in rat liver after bile duct ligation. $\mathrm{Br}$ J Exp Pathol 1978;59:220227.

[19] Katz S, Grosfeld JL, Gross K, Plager DA, Ross D, Rosenthal RS, et al. Impaired bacterial clearance and trapping in obstructive jaundice. Ann Surg 1984; 199:14-20. doi: 10.1097/00000658-198401000-00003.

[20] Pohl J, Ring A, Stremmel W, Stiehl A. The role of dominant stenoses in bacterial infections of bile ducts in primary sclerosing cholangitis. Eur J Gastroenterol Hepatol 2006;18:69-74. doi: 10.1097/00042737-20060100000012.

[21] Chapman R, Fevery J, Kalloo A, Nagorney DM, Boberg KM, Shneider B, et al. Diagnosis and management of primary sclerosing cholangitis. Hepatology 2010;51:660-678. doi: 10.1002/hep.23294.

[22] Negm AA, Schott A, Vonberg RP, Weismueller TJ, Schneider AS, Kubicka S, et al. Routine bile collection for microbiological analysis during cholangiography and its impact on the management of cholangitis. Gastrointest Endosc 2010; 72:284-291. doi: 10.1016/j.gie.2010.02.043.

[23] Mistilis SP, Skyring AP, Goulston SJ. Effect of long-term tetracycline therapy, steroid therapy and colectomy in pericholangitis associated with ulcerative colitis. Australas Ann Med 1965;14:286-294. doi: 10.1111/imj.1965.14. 4.286

[24] Cox KL, Cox KM. Oral vancomycin: treatment of primary sclerosing cholangitis in children with inflammatory bowel disease. J Pediatr Gastroenterol Nutr 1998;27:580-583. doi: 10.1097/00005176-199811000-00015.

[25] Singh PK, Schaefer AL, Parsek MR, Moninger TO, Welsh MJ, Greenberg EP. Quorum-sensing signals indicate that cystic fibrosis lungs are infected with bacterial biofilms. Nature 2000;407:762-764. doi: 10.1038/35037627.

[26] Prince MI, Burt AD, Jones DE. Hepatitis and liver dysfunction with rifampicin therapy for pruritus in primary biliary cirrhosis. Gut 2002;50:436-439. doi: 10.1136/gut.50.3.436.

[27] Perlroth J, Kuo M, Tan J, Bayer AS, Miller LG. Adjunctive use of rifampin for the treatment of Staphylococcus aureus infections: a systematic review of the literature. Arch Intern Med 2008;168:805-819. doi: 10.1001/archinte. 168.8.805.

[28] Al-Bakri AG, Othman G, Bustanji Y. The assessment of the antibacterial and antifungal activities of aspirin, EDTA and aspirin-EDTA combination and their effectiveness as antibiofilm agents. J Appl Microbiol 2009;107:280-286. doi: 10.1111/j.1365-2672.2009.04205.x.

[29] Choi J, Ghoz HM, Peeraphatdit T, Baichoo E, Addissie BD, Harmsen WS, et al. Aspirin use and the risk of cholangiocarcinoma. Hepatology 2016;64: 785-796. doi: 10.1002/hep.28529. 
[30] Ambalam P, Kondepudi KK, Nilsson I, Wadström T, Ljungh A. Bile enhances cell surface hydrophobicity and biofilm formation of bifidobacteria. Appl Biochem Biotechnol 2014;172:1970-1981. doi: 10.1007/s12010-0130596-1.

[31] Merritt JH, Kadouri DE, O'Toole GA. Growing and analyzing static biofilms. Curr Protoc Microbiol 2005; Chapter 1:Unit 1B.1. doi: 10.1002/ 9780471729259.mc01b01s00.

[32] Begley M, Kerr C, Hill C. Exposure to bile influences biofilm formation by Listeria monocytogenes. Gut Pathog 2009;1:11. doi: 10.1186/1757-47491-11.

[33] Lindor KD, Kowdley KV, Luketic VA, Harrison ME, McCashland T, Befeler AS, et al. High-dose ursodeoxycholic acid for the treatment of primary sclerosing cholangitis. Hepatology 2009;50:808-814. doi: 10.1002/hep.23082.

[34] Swidsinski A, Weber J, Loening-Baucke V, Hale LP, Lochs H. Spatial organization and composition of the mucosal flora in patients with inflammatory bowel disease. J Clin Microbiol 2005;43:3380-3389. doi: 10.1128/JCM.43. 7.3380-3389.2005.

[35] Høiby N, Bjarnsholt T, Moser C, Bassi GL, Coenye T, Donelli G, et al. ESCMID guideline for the diagnosis and treatment of biofilm infections 2014. Clin Microbiol Infect 2015;21:S1-S25. doi: 10.1016/j.cmi.2014.10.024.

[36] Färkkilä M, Karvonen AL, Nurmi H, Nuutinen $H$, Taavitsainen M, Pikkarainen $\mathrm{P}$, et al. Metronidazole and ursodeoxycholic acid for primary sclerosing cholangitis: a randomized placebo-controlled trial. Hepatology 2004;40: 1379-1386. doi: 10.1002/hep.20457.

[37] Silveira MG, Torok NJ, Gossard AA, Keach JC, Jorgensen RA, Petz JL, et al. Minocycline in the treatment of patients with primary sclerosing cholangitis: results of a pilot study. Am J Gastroenterol 2009;104:83-88. doi: 10.1038/ ajg.2008.14.

[38] Tabibian JH, Weeding E, Jorgensen RA, Petz JL, Keach JC, Talwalkar JA, et al. Randomised clinical trial: vancomycin or metronidazole in patients with primary sclerosing cholangitis - a pilot study. Aliment Pharmacol Ther 2013;37:604-612. doi: 10.1111/apt.12232.

[39] Davies YK, Tsay CJ, Caccamo DV, Cox KM, Castillo RO, Cox KL. Successful treatment of recurrent primary sclerosing cholangitis after orthotopic liver transplantation with oral vancomycin. Case Rep Transplant 2013;2013: 314292. doi: 10.1155/2013/314292.

[40] Boner AL, Peroni D, Bodini A, Delaini G, Piacentini G. Azithromycin may reduce cholestasis in primary sclerosing cholangitis: a case report and serendipitous observation. Int J Immunopathol Pharmacol 2007;20:847-849. doi: $10.1177 / 039463200702000423$.

[41] Rankin JG, Boden RW, Goulston SJ, Morrow W. The liver in ulcerative colitis; treatment of pericholangitis with tetracycline. Lancet 1959;2:1110-1112. doi: 10.1016/S0140-6736(59)90098-4.

[42] Mathew KK. Metronidazole in primary cholangitis. J Indian Med Assoc 1983 $80: 31,33$. 